\title{
Clinical results following robotic navigation guidance for sacroiliac joint fusion in 36 patients
}

\author{
Jennyfer Paulla Galdino Chaves, MD, Joseph Maalouly, MD, and \\ John Yun Seo Choi, MBChB, FRACS, FAOrthA
}

Spine Ortho Clinic, Melbourne, Victoria, Australia

\begin{abstract}
OBJECTIVE In this study, the authors aimed to describe a new technique of sacroiliac joint (SIJ) fusion using a robotic navigation guidance system and to document clinical results with patient-reported visual analog scale (VAS) scores.

METHODS Patients diagnosed with SIJ dysfunction were surgically treated using 2 hydroxyapatite (HA)-coated, threaded screws with the aid of the robotic navigation system. In a total of 36 patients, 51 SIJs were fused during the study period. Patients' VAS scores were used to determine clinical improvement in pain. Postoperative imaging at routine intervals during the follow-up period was also performed for assessment of radiological fusion. In addition, complication events were recorded, including reoperations.
\end{abstract}

RESULTS All 36 patients had successful fusion evidenced by both CT and clinical assessment at the final follow-up. Two patients underwent reoperation because of screw loosening. The mean preoperative VAS score was $7.2 \pm 1.1$, and the mean 12-month postoperative VAS score was $1.6 \pm 1.46$. This difference was statistically significant $(p<0.05)$ and demonstrated a substantial clinical improvement in pain.

CONCLUSIONS Robotic navigation-assisted SIJ fusion using $2 \mathrm{HA}$-coated, threaded screws placed across the joint was an acceptable technique that demonstrated reliable clinical results with a significant improvement in patient-reported VAS pain scores.

https://thejns.org/doi/abs/10.3171/2021.10.FOCUS21523

KEYWORDS sacroiliac joint fusion; minimally invasive surgery; robotic surgery

$\mathrm{S}$ ACROILIAC joint (SIJ) pain can mimic radicular or discogenic pain localized to the lower back, gluteal, or sacral regions, posing a challenge in diagnosis and treatment. ${ }^{1}$ In a large retrospective study by Bernard and Kirkaldy-Willis in 1987, low-back pain was reported in $22.5 \%$ of 1293 patients with SIJ dysfunction. ${ }^{2}$ Other authors have described similar findings, reporting a symptomatic SIJ dysfunction prevalence rate of $15 \%$ to $30 \%$ in patients presenting with low-back pain. ${ }^{3}$ Additionally, altered biomechanics of the lower back, secondary to osteoarthritis, inflammatory arthritis, or trauma, as well as spine fusion, causes overloading of the SIJ leading to hypermobility or aberrant joint mechanics. ${ }^{4}$ Approximately $20 \%$ of women experience peripartum low-back pain, with the SIJ being the source of pain in $75 \%$. A combination of hormonal, biomechanical, traumatic, and degenerative factors have been known to cause SIJ dysfunction in these postpartum states. ${ }^{5} \mathrm{Ha}$ et al. reported that approximately $40 \%$ of lumbosacral fusions exhibited radiographic degeneration of the SIJ at 5 years. ${ }^{6,7}$
Management options for patients with SIJ pain have mainly focused on physical therapy and pain management methods involving medication, CT-guided SIJ injections, and sacral nerve radiofrequency ablation. For patients with chronic SIJ pain that is not amenable to conservative therapy, traditional open SIJ fusion is an option, although it is plagued with large incisions, autologous bone graftrelated morbidity, long hospital stays, and postoperative non-weight-bearing, leading to an increase in patient morbidity. ${ }^{8}$ To overcome the morbidity associated with traditional open SIJ fusion surgery, minimally invasive surgery (MIS) approaches are being explored with percutaneous placement of implants, with good clinical results. ${ }^{9}$ Significant improvement in symptoms after MIS SIJ fusion in carefully selected patients with postpartum SIJ dysfunction has been reported. ${ }^{5}$ In addition, there has been a report of percutaneously placed, hollow, modular anchorage screws for SIJ fusion with significant improvement in clinical scores at the 24-month follow-up. ${ }^{4}$

The use of intraoperative fluoroscopy to aid implant

ABBREVIATIONS HA = hydroxyapatite; MIS = minimally invasive surgery; SIJ = sacroiliac joint; VAS = visual analog scale.

SUBMITTED August 31, 2021. ACCEPTED October 13, 2021.

INCLUDE WHEN CITING DOI: 10.3171/2021.10.FOCUS21523. 


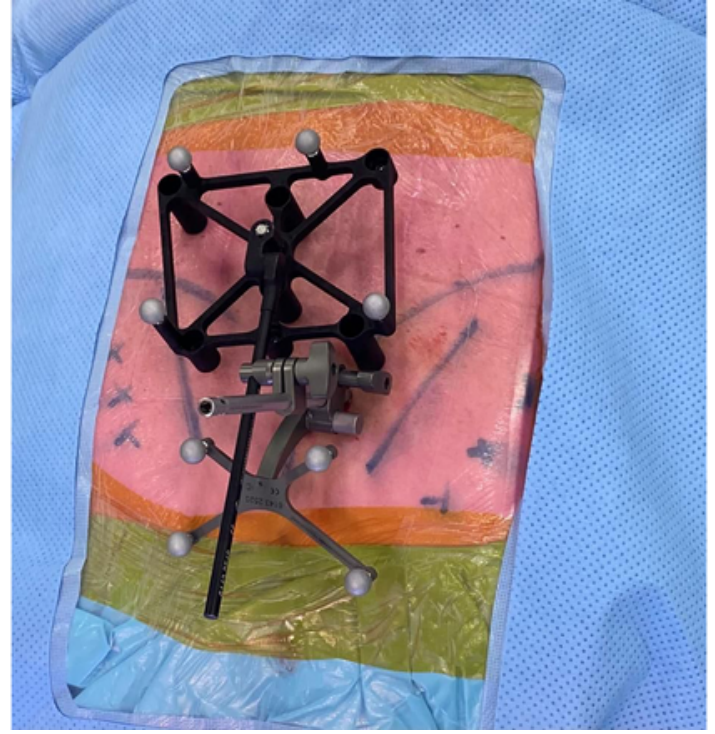

FIG. 1. Photograph of the ExcelsiusGPS robotic navigation platform setup.

placement has been described extensively, including in SIJ fusion surgeries. However, stereotactic intraoperative image guidance with real-time navigated screw placement has been postulated to provide precise implant placement using MIS approaches. Darr et al. reported high satisfaction rates at 3 years following the use of triangular titanium implants inserted using a minimally invasive technique. ${ }^{10}$ Our study aims to describe a new technique using a robotic guidance navigation system (ExcelsiusGPS, Globus Medical) with synthetic bone graft inside hydroxyapatite (HA)-coated screws (SI-LOK, Globus Medical) for SIJ fusion and to document the clinical improvement as a secondary outcome after SIJ fusions using the visual analog scale (VAS) for pain.

\section{Methods Inclusion Criteria}

A retrospective review of 36 consecutive patients who underwent SIJ fusion, with a total of 51 SIJs fused, using intraoperative 3D CT acquisition (O-arm system, Medtronic) and the ExcelsiusGPS robotic navigation platform (Globus Medical) was performed. The study included all patients older than 30 years who were diagnosed with SIJ dysfunction. All patients underwent comprehensive evaluation with a history of symptoms, clinical testing such as the thigh thrust, Gaenslen's test, compression, and the sacral-thrust test for SIJ dysfunction, including CT-guided injections. Radiological evidence of SIJ dysfunction was also recorded. All other conditions causing similar symptoms were ruled out before confirming the diagnosis of SIJ dysfunction. Patients with a history of SIJ fractures, tumors, or infections were excluded from the study. Patient demographics (age, sex, and smoking status), preoperative VAS scores, unilateral or bilateral joint fusion, and previous anterior or posterior fixation were noted in all cases.

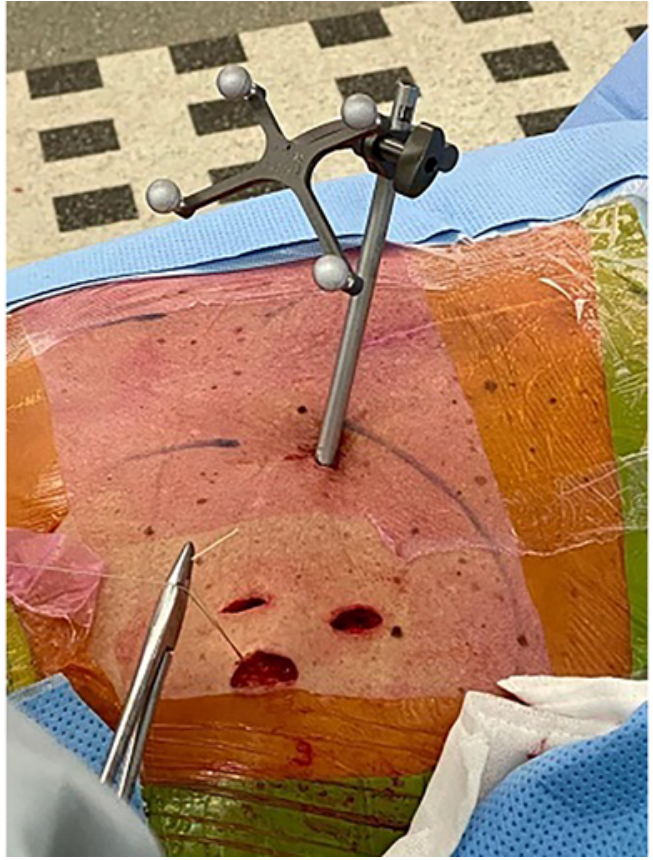

FIG. 2. Photograph illustrating a $1.5-\mathrm{cm}$ incision carried deep to the level of the bone.

\section{Indication for Surgery}

All patients were initially treated with a conservative management protocol using physiotherapy, antiinflammatory medications, and SIJ pain block. Patients for whom 6 months of conservative management failed were offered surgical fusion. Follow-up was planned at 4 weeks, 3 months, 6 months, and 12 months. Erect radiographs were performed immediately, 3 months, and 1 year after surgery. A CT scan was obtained at the 6-month follow-up in patients who did not show clinical improvement at 3 months. VAS scores were collected at 12 months.

Informed consent was obtained from each patient participating in the study, and IRB approval was also obtained.

\section{Surgical Technique}

The patients were placed under general anesthesia and positioned prone on a Wilson frame. Sterile draping was done to expose both the buttocks and the lumbar spine. A 5 -mm longitudinal stab incision was made over the posterior superior iliac spine for placement of the navigation reference frame to provide an imaging reference for the ExcelsiusGPS platform (Fig. 1). An intraoperative CT scan was obtained using the $\mathrm{O}$-arm 2 system (Medtronic). Integration of the CT scan was performed with the ExcelsiusGPS. Using the navigation instruments, the entry points to accommodate 2 or 3 screws were marked on the skin after confirming the planned trajectory in axial, sagittal, and coronal images. A small, $1.5-\mathrm{cm}$ incision was made over each marked skin incision and carried deep to the level of the bone (Fig. 2). Using a navigated cannula, a navigated drill was placed as perpendicular to the synovial SIJ as possible. A navigated high-speed drill was then passed, 


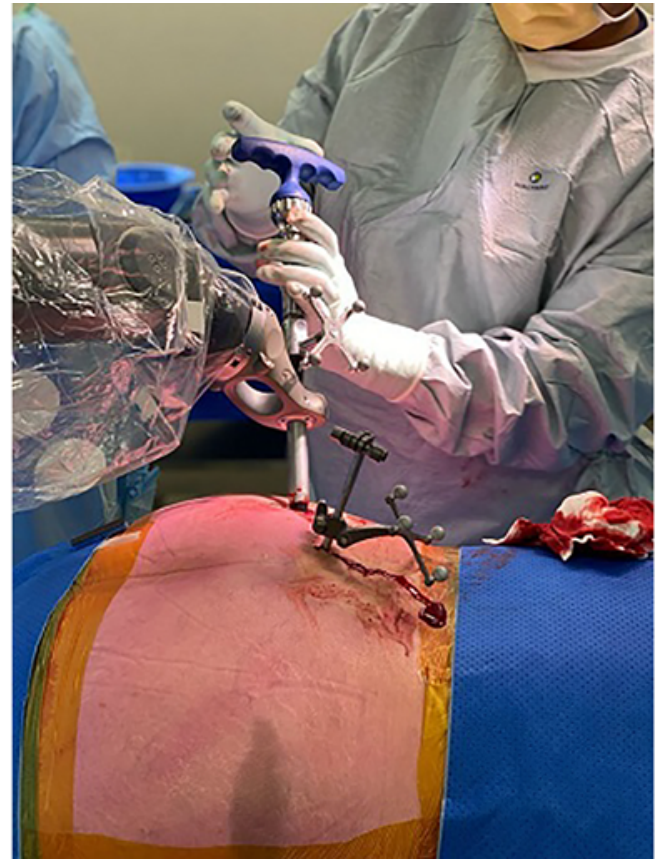

FIG. 3. Intraoperative photograph showing the navigated high-speed drill keeping the navigation interface trajectory.

keeping to the trajectory, using the navigation interface (Fig. 3). The most common pattern used 2 screws across the SIJ. The length and diameter of each implant were estimated based on navigated projections. The screws were placed using preplanned trajectories on the CT scan navigation interface of the robot. Convenient direct placement of screws was possible through the incision after drilling and tapping through the rigid robot guidance arm. Fixation was provided using cannulated screws (SI-LOK SIJ fixation system) filled with allograft and autograft bone from drilling. All incisions were closed in standard fashion. In the postoperative period, patients were allowed immediate weight-bearing and mobilization, as tolerated.

\section{Results}

A total of 36 patients underwent 51 SIJ fusions. The cohort comprised 22 females and 14 males with a mean age of $66 \pm 14.34$ years (range 33-88 years). All patients except one were non-active smokers. Twenty-two patients were diagnosed with primary SIJ dysfunction; 2 patients with primary SIJ dysfunction had undergone a trial with spinal stimulators, without any effect. Twelve patients had previous lumbosacral fusion and 2 patients had a floating lumbar fusion, with the fusion construct ending at L5 with a functional L5-S1 motion segment. The minimum follow-up was 12 months, with a mean follow-up of 13.3 months. Two patients had loosening of the screws and underwent revision surgery. Descriptive data are demonstrated in Table 1.

\section{Functional Outcome}

The Student t-test was used to compare the mean preoperative VAS SIJ pain score $(7.2 \pm 1.1$, range $4-10)$, with the mean postoperative VAS SIJ pain score at the
TABLE 1. Descriptive analysis of patients

\begin{tabular}{cc}
\hline & Value $(\mathrm{n}=36)$ \\
\hline Mean age \pm SD, yrs & $66 \pm 14.3$ \\
\hline Sex, $\mathrm{n}(\%)$ & \\
\hline $\mathrm{M}$ & $14(38.9)$ \\
\hline $\mathrm{F}$ & $22(61.1)$ \\
\hline Fusion, $\mathrm{n}(\%)$ & \\
\hline Unilat & $21(58.3)$ \\
\hline Bilat & $15(41.7)$ \\
\hline Total no. of SIJs fused & 51 \\
\hline
\end{tabular}

12-month, final follow-up (1.6 \pm 1.4$)$, the difference of which was statistically significant $(p<0.05)$. Thirty-four patients reported significant improvement in pain scores at the final follow-up (Table 2).

\section{Discussion}

SIJ pathology can have variable presentations. Goldthwait and Osgood ${ }^{11}$ first reported that the SIJ can be a source of unexplained buttock, low-back, and leg pain. Such nonspecific presentation requires a thorough clinical assessment to correctly identify the pain generators. Often positive provocation maneuvers such as the FABER test, Gaenslen test, and thigh thrust, along with a marked reduction of symptoms on image-guided SIJ injection, can be considered reliable markers for diagnosing SIJ-related pain and excluding other pathologies..$^{12-14}$

Several fusion techniques have been described for SIJ arthrodesis, but debate continues regarding the best MIS method for SIJ fusion. Such open techniques, even modified with the use of modern fixation devices, are associated with increased blood loss, longer surgical time, and mixed results. ${ }^{8,13,15}$ In contrast, Rudolf ${ }^{16}$ studied a cohort of 50 patients who underwent percutaneous fusion using the iFuse Implant System (SI-BONE, Inc.), a triangular titanium implant system for SIJ arthritis; the author found favorable clinical outcomes, with $82 \%$ of patients reporting significant clinical improvements at all time points. Another study reported long-lasting clinical improvements using iFuse over a 5-year follow-up period. ${ }^{17}$ Similarly, studies by Khurana et al. ${ }^{18}$ and Mason et al..$^{19}$ reported encouraging outcomes using hollow, modular anchorage screws for SIJ fusion by a minimally invasive approach. Minimally invasive techniques show promising early and midterm results.

MIS SIJ fusions are not without shortcomings. Zaidi et al. ${ }^{20}$ reviewed several studies including 299 MIS SIJ fu-

TABLE 2. Comparison of preoperative and postoperative VAS scores

\begin{tabular}{lc}
\hline & Value \\
\hline Mean preop VAS score \pm SD & $7.2 \pm 1.1$ \\
\hline Mean postop VAS score \pm SD at final follow-up & $1.6 \pm 1.4$ \\
\hline$p$ value & $<0.05$ \\
\hline
\end{tabular}


sions with a mean follow-up of 21 months. They reported radiographically confirmed fusion rates from $18 \%$ to $100 \%$; however, this review noted that more than $80 \%$ of studies did not include imaging-confirmed anatomical fusions as part of the outcomes assessment. Duhon et al. ${ }^{21} \mathrm{re}-$ ported a bridging bone fusion across the SIJ in $87 \%$ of patients at the 12-month follow-up using a percutaneous SIJ arthrodesis with triangular implants. Fusion rates for MIS sacroiliac fusion from other studies with dedicated radiographic imaging have been reported from $87 \%$ to $97 \%$. $^{21,22}$ Beck et al. reported a fusion rate of $96.9 \%$ in 20 patients after using INFUSE bone graft consisting of rhBMP-2 in conjunction with a single-threaded titanium cage (INTER FIX, Medtronic), with a mean follow-up of 27 months. ${ }^{23}$ The current study reports a progressive fusion trend over 12 months of follow-up. We hypothesize that larger bone and an HA coating with a slotted screw in the SI-LOK system, along with bone graft, might allow rapid fusion across the SIJ; this is based on our historical, yet unpublished, data.

A few studies have reviewed the complications of MIS SIJ fusion. Reoperation rates of $0 \%$ to $17 \%$ have been reported in the literature. ${ }^{24}$ In our study, 2 of $36(5.5 \%)$ patients underwent reoperation due to loosening of the S2 screw. In one of these patients, the SIJ was deemed fused but an additional third screw was inserted to augment the fusion across the SIJ, whereas in the other patient, fearing nonunion across the joint, the loose screw was replaced with a large-bore rescue screw at the surgeon's discretion. A recent study by Schoell et al. ${ }^{25}$ identified a complication rate of $16.4 \%$ in MIS SIJ fusions at the 6-month followup; however, they did not include new lumbar pathology, infection, and postoperative pain in their assessment. We did not encounter any complication of infection or novel lumbar pathology. Pain persisted in 2 patients who reported VAS scores of 5 and 6, even at the 12-month follow-up; for these patients, we believe that the persistence of pain was due to multimodal pain generators and not specifically from SIJ dysfunction.

The MIS technique relies on stabilization of the joint without direct fusion with decortication and has potential for delayed loosening. There is no consensus regarding the number of implants needed to achieve fusion across the SIJ. In our experience, we have noticed that a two-screw construct may be adequate in most cases, given the actual data on SIJ fusion. A single implant may allow continued micromotion across the joint leading to delayed fusion or nonunion. ${ }^{26}$ On the contrary, a three-implant construct provides complete stability compared with one or two implants, and reduces the complications associated with two implants, as shown by finite element analysis. ${ }^{27}$

This study reports a significant clinical improvement and reduction in postoperative VAS scores over the course of the follow-up. Final follow-up for clinical scores was done at 12 months. The patient-reported mean postoperative VAS score $(1.6 \pm 1.4)$ showed statistically significant improvement $(\mathrm{p}<0.05)$ compared with the mean preoperative VAS score $(7.2 \pm 1.1)$.

\section{Conclusions}

Our results have demonstrated that robot-assisted per- cutaneous SIJ fusion using SI-LOK screws and synthetic bone graft significantly improves pain in the treatment of SIJ dysfunction with an acceptable complication profile and reliable radiological fusion by 12 months. This may be explained, in part, by minimal tissue trauma from the surgical approach and precise placement of implants.

\section{References}

1. Sembrano JN, Polly DW Jr. How often is low back pain not coming from the back? Spine (Phila Pa 1976). 2009;34(1): E27-E32.

2. Bernard TN Jr, Kirkaldy-Willis WH. Recognizing specific characteristics of nonspecific low back pain. Clin Orthop Relat Res. 1987;(217):266-280.

3. Schwarzer AC, Aprill CN, Bogduk N. The sacroiliac joint in chronic low back pain. Spine (Phila Pa 1976). 1995;20(1):31-37.

4. Al-Khayer A, Hegarty J, Hahn D, Grevitt MP. Percutaneous sacroiliac joint arthrodesis: a novel technique. J Spinal Disord Tech. 2008;21(5):359-363.

5. Capobianco R, Cher D; SIFI Study Group. Safety and effectiveness of minimally invasive sacroiliac joint fusion in women with persistent post-partum posterior pelvic girdle pain: 12-month outcomes from a prospective, multi-center trial. Springerplus. 2015;4(1):570.

6. Liliang PCLK, Lu K, Liang CL, Tsai YD, Wang KW, Chen HJ. Sacroiliac joint pain after lumbar and lumbosacral fusion: findings using dual sacroiliac joint blocks. Pain Med. 2011;12(4):565-570.

7. Ha KY, Lee JS, Kim KW. Degeneration of sacroiliac joint after instrumented lumbar or lumbosacral fusion: a prospective cohort study over five-year follow-up. Spine (Phila Pa 1976). 2008;33(11):1192-1198.

8. Smith-Petersen MN. Arthrodesis of the sacroiliac joint. A new method of approach. J Bone Joint Surg Am. 1921;3(8):400-405.

9. Rudolf L. MIS fusion of the SI joint: does prior lumbar spinal fusion affect patient outcomes? Open Orthop J. 2013; 7:163-168.

10. Darr E, Meyer SC, Whang PG, Kovalsky D, Frank C, Lockstadt $\mathrm{H}$, et al. Long-term prospective outcomes after minimally invasive trans-iliac sacroiliac joint fusion using triangular titanium implants. Med Devices (Auckl). 2018;11:113-121.

11. Goldthwait JE, Osgood RB. A consideration of the pelvic articulations from an anatomical, pathological and clinical standpoint. Boston Med Surg J. 1905;152:593-601.

12. Bernard TN Jr, Cassidy JD. The sacroiliac joint syndrome: pathophysiology, diagnosis, and management. In: Frymoyer JW, ed. The Adult Spine: Principles and Practice. Raven Press; 1991:2107-2130.

13. Dreyfuss P, Michaelsen M, Pauza K, McLarty J, Bogduk N. The value of medical history and physical examination in diagnosing sacroiliac joint pain. Spine (Phila Pa 1976). 1996; 21(22):2594-2602.

14. Schütz U, Grob D. Poor outcome following bilateral sacroiliac joint fusion for degenerative sacroiliac joint syndrome. Acta Orthop Belg. 2006;72(3):296-308.

15. Kim JT, Rudolf LM, Glaser JA. Outcome of percutaneous sacroiliac joint fixation with porous plasma-coated triangular titanium implants: an independent review. Open Orthop J. 2013;7:51-56.

16. Rudolf L. Sacroiliac joint arthrodesis-MIS technique with titanium implants: report of the first 50 patients and outcomes. Open Orthop J. 2012;6:495-502.

17. Rudolf L, Capobianco R. Five-year clinical and radiographic outcomes after minimally invasive sacroiliac joint fusion using triangular implants. Open Orthop J. 2014;8:375-383.

18. Khurana A, Guha AR, Mohanty K, Ahuja S. Percutaneous fusion of the sacroiliac joint with hollow modular anchorage 
screws: clinical and radiological outcome. J Bone Joint Surg Br. 2009;91(5):627-631.

19. Mason LW, Chopra I, Mohanty K. The percutaneous stabilisation of the sacroiliac joint with hollow modular anchorage screws: a prospective outcome study. Eur Spine J. 2013; 22(10):2325-2331.

20. Zaidi HA, Montoure AJ, Dickman CA. Surgical and clinical efficacy of sacroiliac joint fusion: a systematic review of the literature. J Neurosurg Spine. 2015;23(1):59-66.

21. Duhon BS, Bitan F, Lockstadt H, Kovalsky D, Cher D, Hillen T. Triangular titanium implants for minimally invasive sacroiliac joint fusion: 2-year follow-up from a prospective multicenter trial. Int J Spine Surg. 2016;10:13.

22. Abbasi H, Hipp JA. The assessment of fusion following sacroiliac joint fusion surgery. Cureus. 2017;9(10):e1787.

23. Beck CE, Jacobson S, Thomasson E. A retrospective outcomes study of 20 sacroiliac joint fusion patients. Cureus. 2015;7(4):e260.

24. Wise CL, Dall BE. Minimally invasive sacroiliac arthrodesis: outcomes of a new technique. J Spinal Disord Tech. 2008;21(8):579-584.

25. Schoell K, Buser Z, Jakoi A, Pham M, Patel NN, Hsieh PC, et al. Postoperative complications in patients undergoing minimally invasive sacroiliac fusion. Spine J. 2016;16(11):1324-1332.

26. Cleveland AW III, Nhan DT, Akiyama M, Kleck CJ, Noshchenko A, Patel VV. Mini-open sacroiliac joint fusion with direct bone grafting and minimally invasive fixation using intraoperative navigation. J Spine Surg. 2019;5(1):31-37.
27. Lindsey DP, Kiapour A, Yerby SA, Goel VK. Sacroiliac joint stability: finite element analysis of implant number, orientation, and superior implant length. World J Orthop. 2018;9(3): $14-23$.

\section{Disclosures}

The authors report no conflict of interest concerning the materials or methods used in this study or the findings specified in this paper.

\section{Author Contributions}

Conception and design: all authors. Acquisition of data: all authors. Analysis and interpretation of data: all authors. Drafting the article: all authors. Critically revising the article: all authors. Reviewed submitted version of manuscript: all authors. Approved the final version of the manuscript on behalf of all authors: Chaves. Statistical analysis: all authors. Administrative/technical/ material support: all authors. Study supervision: Choi.

\section{Correspondence}

Jennyfer Paulla Galdino Chaves: Spine Ortho Clinic, Melbourne, Victoria, Australia. jennyfergaldino@hotmail.com. 